\title{
Saint-Saulve - Place Maillard
}

\section{Vincent Maliet}

URL : http://journals.openedition.org/adlfi/9924

ISSN : 2114-0502

Éditeur

Ministère de la culture

\section{Référence électronique}

Vincent Maliet, "Saint-Saulve - Place Maillard », ADLFI. Archéologie de la France - Informations [En ligne], Nord-Pas-de-Calais, mis en ligne le 01 mars 1997, consulté le 30 avril 2019. URL : http:// journals.openedition.org/adlfi/9924

Ce document a été généré automatiquement le 30 avril 2019

(c) Ministère de la Culture et de la Communication, CNRS 


\title{
Saint-Saulve - Place Maillard
}

\author{
Vincent Maliet
}

Date de l'opération : 1990 (SU)

Inventeur(s) : Maliet Vincent

1 La ville de Saint-Saulve a retenu ce site pour implanter sa nouvelle Maison de la Jeunesse et de la Culture (MJC).

2 L'étude d'impact archéologique avait permis d'identifier ce gisement: une ancienne abbaye, fondée au IX ${ }^{\mathrm{e}} \mathrm{s}$. Elle s'était installée à proximité d'une église des $\mathrm{VII}^{\mathrm{e}}-\mathrm{VIII}{ }^{\mathrm{e}} \mathrm{s}$. où la dépouille de Saulve, évêque martyr, reposa vers 740.

3 L'emprise du terrain occupée par les religieux, ultérieurement attachés à Cluny, se matérialisait par un mur épais. Il semblerait, selon M. Racinet, que ce massif s'érigea sous les directives du prieur, en 1451. Rien ne s'oppose à cette datation. Un grand bâtiment, qui connut plusieurs phases d'extension, apparut à proximité. Selon toute vraisemblance, ce dernier se trouvait, partiellement du moins, en sous-sol.

4 Régulièrement espacés, des piliers très rapprochés rythmaient l'espace interne. Des fondations de chaînages ancraient solidement ces assises. La trame présentait de légers décalages dans l'orientation, témoignant ainsi des étapes de la construction. Un puits fut comblé et scellé à la faveur d'une telle campagne. Il apparaît, par ailleurs, que des sépultures de la fin du $\mathrm{VII}^{\mathrm{e}} \mathrm{s}$. subirent une destruction lors de la réalisation de la partie la plus ancienne.

5 Cette nécropole, dont il subsistait quelques tombes, disparut totalement sous les aménagements extérieurs. Des trous de poteaux et un sol de mortier pourraient indiquer l'existence d'une galerie ouverte. La fonction de l'édifice demeure énigmatique. Cependant, une base d'autel qui subsistait dans une chapelle, agencée après obturation de plusieurs baies, tendrait à confirmer une vocation cultuelle. Quelques ensevelissements se pratiquèrent par ailleurs dans les intervalles laissés par le maillage de fondation.

6 Contre ce bâtiment une cave en pierre, profonde et voûtée, possédait un puisard. Une fondation de plan rectangulaire, aux angles arrondis, amputa partiellement l'escalier d'accès. En l'état actuel des recherches, on pense que ce massif correspondrait avec une 
tour, celle-ci figurant sur une vue de l'Album de Croy et datée aux alentours de 1600 . L'enchevêtrement des murailles s'accentue encore lors de l'agrandissement de l'église paroissiale voisine, après la Révolution... Plus loin, un second puits livra, dans son comblement, des restes végétaux, des chaussures de cuir, des sceaux de cire, des outils et de nombreuses céramiques. Cet enfouissement nous ramène vraisemblablement à la crise iconoclaste...

7 Au-delà du mur de clôture, la construction d'un petit lotissement n'avait laissé que peu de traces de l'ancienne église du village. On déplore notamment l'absence de niveaux de sols. Pourtant, une nécropole mérovingienne et carolingienne apparaît relativement bien conservée, en dépit de fréquentes violations de sépultures. Les remblais de fosses livrèrent en abondance de la céramique à dégraissant coquiller.

8 Trois fonds de cabanes doivent encore être mentionnés, ainsi que deux fossés. L'un d'eux possédait un profil en « $V$ », très prononcé. Une fibule et un scéat frison se trouvaient au sein du comblement. De petites dépressions existaient à proximité. Elles correspondraient peut-être à des latrines.

\section{INDEX}

Index chronologique : bas Moyen Âge, ép. carolingienne, ép. mérovingienne

Index géographique : Nord-Pas-de-Calais, Nord (59), Saint-Saulve

operation Sauvetage urgent (SU) 